Society for the Anthropology of Work • Book Forum: Threshold

\title{
No Accident
}

Lawrence J. Ramirez

Published on: Jul 05, 2021

License: Creative Commons Attribution 4.0 International License (CC-BY 4.0). 
In Threshold: Emergency Responders on the US-Mexico Border, Ieva Jusionyte situates the operations of militarized border infrastructures and a weaponized desert landscape within an exploration of the work of harm mitigation, disaster response, and humanitarian resistance. Although this ethnographic study takes as given an understanding of the U.S.-Mexico border as an apparatus of violence that dehumanizes and damages unsanctioned border crossers, Jusionyte also interrogates the seemingly paradoxical mission of emergency response and its complicated interconnections with the border's structure of harm.

In the book's introduction, Jusionyte establishes her ethnographic situation working with Emergency Medical Services (EMS) around the border community of Ambos Nogales, a city split by the border, with one side in the U.S. state of Arizona and the other side in the Mexican state of Sonora. Through participation in the Nogales EMS, Jusionyte learns of and experiences situations of graphic injury that delineate an indirect critique by workers of the structures of violence inherent in the "prevention through deterrence" border strategy. In particular, the term accident is contested by EMS workers; when injuries are reliably replicated by the border infrastructure, whether it is broken limbs at Ankle Alley or fingers severed by the edge of the wall or overloaded vehicles flipped during pursuit, these are understood not as accidents but as designed outcomes. Such gory stories form typologies of harm that can be anticipated by the emergency workers.

Additionally, the political and economic aspects of life at the border lead to the uneven allocation of resources and other complications for emergency responders. As Jusionyte notes, an industrial hazard does not recognize national territories; a chemical spill or toxic cloud on the Mexican side of the border can easily spread onto the U.S. side. Although there may be professional cooperation and camaraderie between the U.S. emergency services and their Mexican counterparts, regulations and border inspections can also delay or disrupt the ability to respond. Thus, insurance policies prevent U.S. EMS personnel from responding to hazards in Mexico, border checks delay Mexican firefighters from responding to clearly visible fire emergencies in the United States, and trade policies impede the movement of goods like bandages and child car seats. The noteworthy exception to these obstructions are highly funded and carefully coordinated preparations for terrorism prevention and response, including training for threat scenarios that have little practical relevance for quotidian operations at the border. Thus, significant wealth and effort is allocated for unlikely nightmare events, while chronic suffering and systemic violence is left underfunded 
and haphazardly localized. To sustain their operations, emergency services end up becoming a de facto adjunct service for the Border Patrol.

Finally, volunteer humanitarian groups, like No More Deaths, provide unsanctioned labor to mitigate the violence of border crossing, leaving water supplies in the desert or offering ibuprofen to offset pain. Medical service camps for migrants offer an alternative to official EMS, allowing the patients anonymity and sanctuary from the Border Patrol. However, their funding, staffing, and medical resources are shown to be inadequate given the volume of harm generated by the border, a mere bandage on a gushing wound. Thus, in Jusionyte's telling, the necropolitical mechanism of the border subverts and overwhelms the labor of care that attempts to stem its devastating effects.

\section{Author Bio}

Lawrence J. Ramirez is a PhD student in the Department of Anthropology at the University of California, Riverside. His research examines exhibitionary places like museums and public parks as sites of labor, spectacle, and accumulation. His research is based in Los Angeles, California, and Sevilla, Spain. 